\title{
Effect of Dioscorea opposita Thunb. (yam) supplementation on physicochemical and sensory characteristics of yogurt
}

\author{
S. H. Kim, S. Y. Lee, G. Palanivel, and H. S. Kwak ${ }^{1}$ \\ Department of Food Science and Technology, Sejong University, Seoul 143-747, Korea
}

\begin{abstract}
A study was conducted to examine the physicochemical, microbial, and sensory properties of yogurt made by supplementing powdered yam Dioscorea opposita Thunb. (YPT) at different concentrations $(0.2,0.4,0.6$, and $0.8 \%, \mathrm{wt} / \mathrm{vol})$ into milk, which was pasteurized and then fermented at $43^{\circ} \mathrm{C}$ for $6 \mathrm{~h}$ and stored for $16 \mathrm{~d}$. The $\mathrm{pH}$ values of all samples decreased, whereas viscosity values and mean microbial counts increased during storage. The $\mathrm{L}^{*}$ and $\mathrm{a}^{*}$ color values (indicators of lightness and redness, respectively) of yogurt samples were not remarkably influenced by adding YPT, whereas the $\mathrm{b}^{*}$ values (indicating yellowness) significantly increased with the addition of YPT at all concentrations at $0 \mathrm{~d}$ of storage, probably due to the original yellow color of yam powder. In functional component analyses, when the concentration of YPT increased, the amount of allantoin and diosgenin proportionally increased. The content of allantoin was 3.22 and diosgenin $4.69 \mu \mathrm{g} / \mathrm{mL}$ when $0.2 \%$ (wt/vol) YPT was supplemented and did not change quantitatively during the storage period (16 d). The sensory test revealed that the overall acceptability scores of YPT-supplemented yogurt samples (0.2 to $0.6 \%, \mathrm{wt} / \mathrm{vol})$ were quite similar to those of the control throughout the storage period of $16 \mathrm{~d}$. Based on the data obtained from the present study, it was concluded that the concentrations ( 0.2 to $0.6 \%$, wt/vol) of YPT could be used to produce YPT-supplemented yogurt without significant adverse effects on physicochemical, microbial, and sensory properties, and enhance functional components from the supplementation.
\end{abstract}

Key words: yam, yogurt, allantoin, supplementation

\section{INTRODUCTION}

Yams (Dioscorea species) serve as an important staple food in many parts of the world (Hariprakash and Nambisan, 1996; Lin and Yang, 2008) and also are used

Received October 11, 2010.

Accepted January 1, 2011.

${ }^{1}$ Corresponding author: kwakhs@sejong.ac.kr for traditional medicine (Shin et al., 2006). Health benefits of yams mainly rely on the functional component, such as allantoin and diosgenin content. Allantoin has a broad range of clinical acceptance (Garnick et al., 1998; $\mathrm{Fu}$ et al., 2006). Ureides (allantoin and allantoic acid) of yams are known to cure inflammation and ulcers in the human body (Sagara et al., 1988). The amount of allantoin varies with species and a high level of allantoin was noted in Dioscorea opposita Thunb. (Ueda and Sasake, 1956). Diosgenin, the aglycone of the yam steroidal saponins, is also used as the raw material for industrial production of steroidal drugs. Some other functional steroidal saponins existing in yams are also identified (Yang et al., 2003). Ma et al. (2002) reported that yam saponins have inhibitory activity against cholesterol absorption.

Yogurt is considered by nutritionists to have high nutritional value because of decreased lactose content and a significant concentration of $\mathrm{Ca}^{++}$, and positive bioactive effects because of the availability of prebiotic ingredients and probiotic bacteria (Lourens-Hattingh and Viljoen, 2001). In recent years, many different food ingredients, including $\beta$-glucan (Sahan et al., 2008), green and black teas (Jaziri et al., 2009), and chitosan (Seo et al., 2009) have been formulated into yogurt formulations to improve the nutritional value. From a technological point of view, the addition of yam powder may have a positive effect on the texture, stability, and the consistency of the yogurt because of the availability of functional ingredients such as allantoin and diosgenin.

To produce a novel yogurt with beneficial health properties, we studied the addition of yam powder (YPT) as a functional ingredient to develop a nutraceutical yogurt from whole milk. No report in the literature exists on the production of the yam powder-supplemented yogurt. Therefore, the objectives of the current study were to investigate (1) the possibility of adding YPT into yogurt, (2) the change in functional components (allantoin and diosgenin) during fermentation, and (3) the effects of adding YPT on the physicochemical, microbial, and sensory properties of the yogurt during storage. 


\section{MATERIALS AND METHODS}

\section{Materials}

Commercial milk (3.6\% milk fat) was purchased from Seoul Dairy Co-op (Seoul, Korea). Yam (YPT) tuber was obtained from the Research Center of Dongyang Industry (Seoul, Korea). These raw tubers were skinned, cut to $0.5-\mathrm{cm}$ thick slices, lyophilized, milled, and then passed through a 100-mesh sieve. The powdered YPT was stored at $4^{\circ} \mathrm{C}$ until use. All chemicals were purchased from Sigma Chemical Co. (St. Louis, MO), and all solvents were of chromatographic grade.

\section{Manufacture of Yam-Enriched Yogurt}

Milk containing $3.6 \%$ fat and $13.4 \%$ total solids was combined with $3.7 \%$ (wt/vol) skim milk powder and different concentrations $(0.2,0.4,0.6$, and $0.8 \%)$ of YPT were blended with a laboratory blender (MS3040, Tops, Misung Co., Seoul, Korea) at $400 \mathrm{rpm}$ for $5 \mathrm{~min}$. Each batch was made with $10 \mathrm{~L}$ of milk (2 L per treatment) at a laboratory scale. The milk with completely solubilized YPT was heated at $90^{\circ} \mathrm{C}$ for $10 \mathrm{~min}$ in a water bath and cooled to approximately $42^{\circ} \mathrm{C}$. A $0.02 \%$ commercial starter culture (Chr. Hansen, Pty. Ltd, Bayswater, Australia) in freeze-dried, direct-to-vat set form containing Lactobacillus bulgaricus, Streptococcus thermophilus, and Bifidobacterium bifidum was added and fermented at $43^{\circ} \mathrm{C}$ for approximately $6 \mathrm{~h}$ until the $\mathrm{pH}$ reached 4.5. After fermentation, each yogurt sample was stored for $0,4,8,12$, and $16 \mathrm{~d}$ at $4^{\circ} \mathrm{C}$ in a refrigerator to evaluate the physicochemical and sensory properties. Each batch of yogurt making was done in triplicate.

\section{pH and Titratable Acidity}

The $\mathrm{pH}$ values of the yogurt samples were measured using a glass electrode $\mathrm{pH}$ meter (Orion 900A, Boston, MA). The titratable acidity (TA) value of each yogurt sample was determined after mixing $9 \mathrm{~mL}$ of yogurt sample with $9 \mathrm{~mL}$ of distilled water containing $0.5 \%$ phenolphthalein as an indicator, and titrated with 0.1 $N \mathrm{NaOH}$ to a faint pink endpoint. All samples were measured in triplicate.

\section{Microbial Analysis}

de Man, Rogosa, and Sharpe (MRS) plate count agar (Difco Laboratories, Detroit, MI) was used for lactic acid bacteria (LAB) counting. One milliliter of yogurt samples was diluted with $9 \mathrm{~mL}$ of sterile peptone and water diluents. Subsequent dilutions of each sample were plated in triplicate and incubated at $37^{\circ} \mathrm{C}$ for 48 h.

\section{Viscosity}

The viscosity of yogurt samples $(100 \mathrm{~mL})$ was measured after mixing of the sample for 5 min at room temperature using a Brookfield viscometer (Model LVDV I+, Version 3.0, Stoughton, MA) with a spindle no. 2 at $60 \mathrm{rpm}$. All samples were measured in triplicate.

\section{Color}

Color values of each yogurt sample were investigated using a colorimeter (CR210, Minolta, Tokyo, Japan) by holding the colorimeter above the sample, after calibrating its original value with a standard plate. $(\mathrm{X}=$ $97.83, Y=81.58, \mathrm{Z}=91.51)$. Measured $\mathrm{L}^{*}, \mathrm{a}^{*}$, and $\mathrm{b}^{*}$ values were used as indicators of lightness, redness, and yellowness, respectively. All samples were measured in triplicate.

\section{Allantoin and Diosgenin Content}

To $10 \mathrm{~mL}$ of yogurt samples, 10 to 15 times of $95 \%$ ethanol (vol/vol) was added, and the mixture was ultrasonicated using a sonicator (Branson 3210, Branson Ultrasonics Corporation, Danbury, CT) for $10 \mathrm{~min}$ at $4^{\circ} \mathrm{C}$. The sample was stored overnight at $4^{\circ} \mathrm{C}$. The supernatant formed after stored at $4^{\circ} \mathrm{C}$ was evaporated on a temperature-controlled water bath (Koma, Prime Tech, Seoul, Korea) at $40^{\circ} \mathrm{C}$ for $5 \mathrm{~min}$. Four milliliters of distilled water was added and the sample was ultrasonicated for $30 \mathrm{~min}$ at $4^{\circ} \mathrm{C}$. One milliliter of sample was taken and centrifuged at $7,700 \times g$ for $15 \mathrm{~min}$. The supernatant was then filtered through a $0.45-\mu \mathrm{m}$ nylon syringe filter (Whatman International Ltd., Maidstone, England) and then injected for analysis.

Allantoin and diosgenin were analyzed using an Agilent 1,200 Series HPLC system with an Agilent 1,200 series diode-array detector (Agilent Technologies, Santa Clara, CA) and Waters SunFire $\mathrm{C}_{18} 5 \mu \mathrm{m}(4.6 \mathrm{~mm} \times$ $250 \mathrm{~mm}$ ) column (Milford, MA), with isocratic elution buffer. The conditions for allantoin were as follows: mobile phase: $\mathrm{CH}_{3} \mathrm{CH}_{2} \mathrm{OH} / \mathrm{CHCl}_{3} / \mathrm{H}_{2} \mathrm{O} \quad(0.5 / 0.012 / 100)$; flow rate: $0.2 \mathrm{~mL} / \mathrm{min}$ for 1 through $5 \mathrm{~min}$, increasing to $0.5 \mathrm{~mL} / \mathrm{min}$ after $5 \mathrm{~min}$ and holding at this rate through $15 \mathrm{~min}$ - then the flow was decreased to 0.2 $\mathrm{mL} / \mathrm{min}$ and held through $20 \mathrm{~min}$; detection was at $215 \mathrm{~nm}$; injection volume: $20 \mu \mathrm{L}$. For diosgenin, mobile phase: $\mathrm{CH}_{3} \mathrm{CHOHCH}_{3} / \mathrm{CH}_{3} \mathrm{CN} / \mathrm{H}_{2} \mathrm{O}(60 / 30 / 10)$; flow rate: $0.7 \mathrm{~mL} / \mathrm{min}$; UV wavelength: $213 \mathrm{~nm}$; and injection volume: $20 \mu \mathrm{L}$. The allantoin and diosgenin were quantified using the respective external standards. 


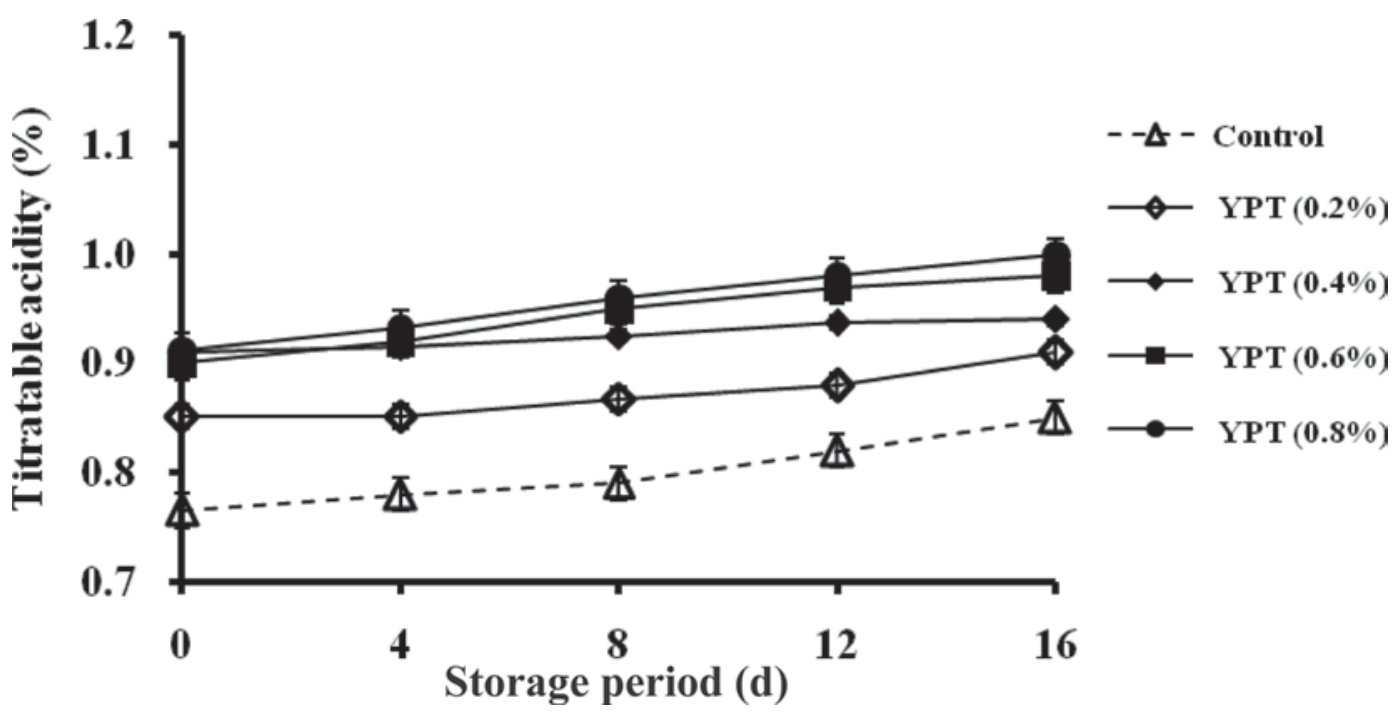

Figure 1. Changes in titratable acidity of powdered yam (Dioscorea opposita Thunb.; YPT)-supplemented yogurt stored at $4^{\circ} \mathrm{C}$ for $16 \mathrm{~d}$. At $0 \mathrm{~d}$, yogurt had been stabilized for $24 \mathrm{~h}$.

A standard graph for each was prepared by plotting concentration versus area. Quantification was carried out from integrated peak areas of the sample and corresponding standard graph.

\section{Sensory Analysis}

The sensory evaluation was performed by 8 trained panelists, who were the graduate students (4 males and 4 females) in the Dairy Products Laboratory (Food Science and Technology Department, Sejong University, Seoul, Korea), aged 25 to $33 \mathrm{yr}$, and familiar with yogurt consumption. Panelists were trained in 2 sessions using a 7-point scale, where 1 represented very weak herb (yam) flavor, yellow color, and taste, and 7 represented very strong herb flavor, yellow color, and taste. Reference samples prepared at the level of $0,0.4$, and $0.8 \%$ YPT-supplemented yogurt were kept in a closed cup for 0,8 , and $16 \mathrm{~d}$, representing the score of 1,4 , and 7 , respectively. To test the flavor of samples, the panelists were asked to open the closed cup and sniff the headspace above the samples. The samples were then scored.

\section{Statistical Analysis}

All statistical analyses were performed using SAS version 9.0 (SAS Institute, 2002). An ANOVA was performed using the general linear models procedure to determine significant differences among the samples. Means were compared by using Duncan's multiple range test $(P<0.05)$.

\section{RESULTS AND DISCUSSION}

\section{Titratable Acidity}

The changes in TA values of the yogurt sample supplemented with different concentrations of YPT and of the control (without yam powder) during $16 \mathrm{~d}$ of storage at $4^{\circ} \mathrm{C}$ are shown in Figure 1. Adding YPT at various levels $(0.2,0.4,0.6$, and $0.8 \%$, wt/vol $)$ into the yogurt increased the values of TA at $0 \mathrm{~d}$. Further increasing the storage period from 0 to $16 \mathrm{~d}$ also significantly increased the TA values $(P<0.05)$. This was well correlated with $\mathrm{pH}$ (data not shown), which showed a decrease with increasing storage period and existed in the range of 4.51 to 4.34 , which is considered to be an acceptable range for commercial yogurt (Sahan et al., 2008; Seo et al., 2009). Even though a significant difference was found in TA values between the control and different treatments $(P<0.05)$, a similar trend was shown and the values were acceptable at various levels ( 0.2 to $0.8 \%$, wt $/ \mathrm{vol}$ ) of YPT addition throughout the storage period. Seo et al. (2009) also observed that chitosan-supplemented yogurt increased in TA with subsequent decrease in $\mathrm{pH}$ as the storage time increased to $20 \mathrm{~d}$. These results indicated that YPT addition at various levels provided less adverse effects on the yogurt TA properties.

\section{Lactic Acid Bacteria Count}

The changes in LAB count of YPT-supplemented yogurt and of the control stored at $4^{\circ} \mathrm{C}$ during $16 \mathrm{~d}$ are shown in Figure 2. At $0 \mathrm{~d}$ of storage, the mean 


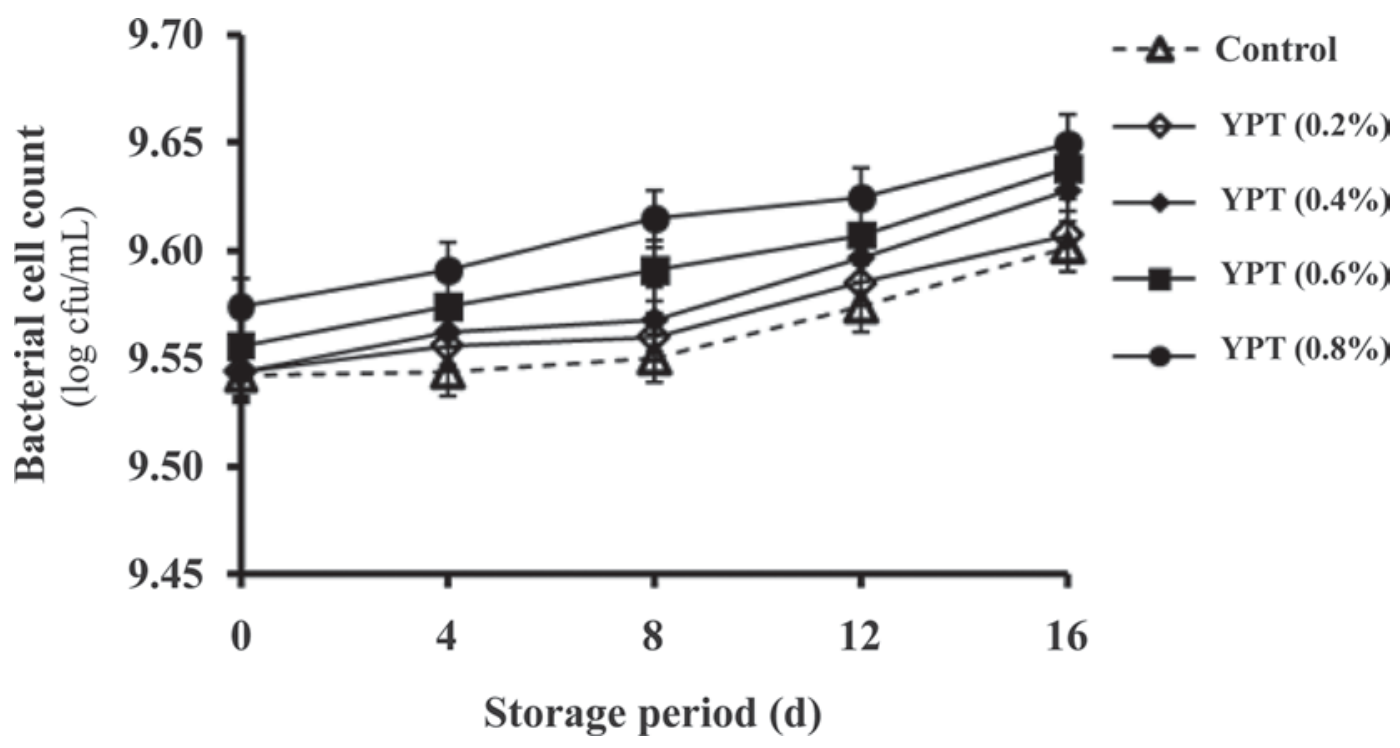

Figure 2. Changes in lactic acid bacteria of powdered yam (Dioscorea opposita Thunb; YPT)-supplemented yogurt stored at $4^{\circ} \mathrm{C}$ for $16 \mathrm{~d}$. At $0 \mathrm{~d}$, yogurt had been stabilized for $24 \mathrm{~h}$.

counts of LAB were not significantly different between the control and the YPT-supplemented yogurt except for supplementation at the level of $0.8 \%(P<0.05)$. Asiedu and Sanni (2002) reported that yam tuber is rich in starch and mucilage, which facilitates the growth of LAB. Increasing the concentration of yam powder in yogurt provides more starch and mucilage with increased counts of LAB from 9.32 to $9.65 \mathrm{log}$ $\mathrm{cfu} / \mathrm{mL}$ as the storage time increased to $16 \mathrm{~d}$. Lactic acid bacteria can also produce enzymes that could hydrolyze starch into reducing sugars (Abodjo Kakou et al., 2010), which can be further metabolized into lactic acids (Coulin et al., 2006; Abodjo Kakou et al., 2010). This was also confirmed by the increase in the TA of yogurt supplemented with YPT during the increased storage time of $16 \mathrm{~d}$ (Figure 1).

\section{Viscosity}

The viscosity values of all the samples increased during $16 \mathrm{~d}$ of storage (Figure 3). However, the viscosity value of the control was not dramatically increased during $16 \mathrm{~d}$ of storage. Viscosity development is related to the aggregation of casein micelles and gel formation and consequently, to the biochemical and physicochemical changes during fermentation of milk (Dalgleish and Law 1988; Singh and Kim, 2009). Yam mucilage contains starch and soluble proteins, such as mannosebinding lectins and dioscorin, which also enhance the viscosity (Myoda et al., 2006). At 0 d of storage, the viscosity value increased with increased concentration of YPT-supplemented yogurt. In our preliminary study, the extracted yam powder (EYP), prepared by the removal of mucilage and starch during the extraction process was added into yogurt. The EYP addition at the higher level of $6 \%$ did not increase the viscosity of yogurt with increasing storage times (data not shown). The findings confirm that YPT mucilage and starch were associated with the viscosity of yogurt. The addition of YPT rich in starch and mucilage may favor interaction of YPT starch with casein in yogurt, which can eliminate the steric repulsion and rapid development of viscosity (Banon and Hardy 1992; Singh and Kim, 2009). Some researchers also postulated that casein in yogurt interacting with starch led to increase in viscosity, but promoting phase separation (Williams et al., 2004; Amaya-Llano et al., 2008). Thus, addition of a lower concentration $(0.2 \%$, wt/vol $)$ of YPT in yogurt may decrease the phase separation with higher viscosity. Increasing values of viscosity were also observed in concentrated yogurt (Sahan et al., 2008; Seo et al., 2009).

\section{Color}

The changes in color of YPT-supplemented yogurt and of the control stored at $4^{\circ} \mathrm{C}$ during $16 \mathrm{~d}$ are presented in Table 1. The $\mathrm{L}^{*}$ and $\mathrm{a}^{*}$ values for all of the samples studied were not considerably changed during storage at $16 \mathrm{~d}$. The values of a* for the control and $0.4 \%$ (wt/vol) YPT supplemented-yogurt were significantly decreased when the storage period increased to $16 \mathrm{~d}$ as compared with other treatments $(P<0.05)$. Shirai et al. (1992) observed that yogurt syneresis induced a decrease in $a^{*}$ values because the whey released by the yogurt contains riboflavin, which has a very important green 


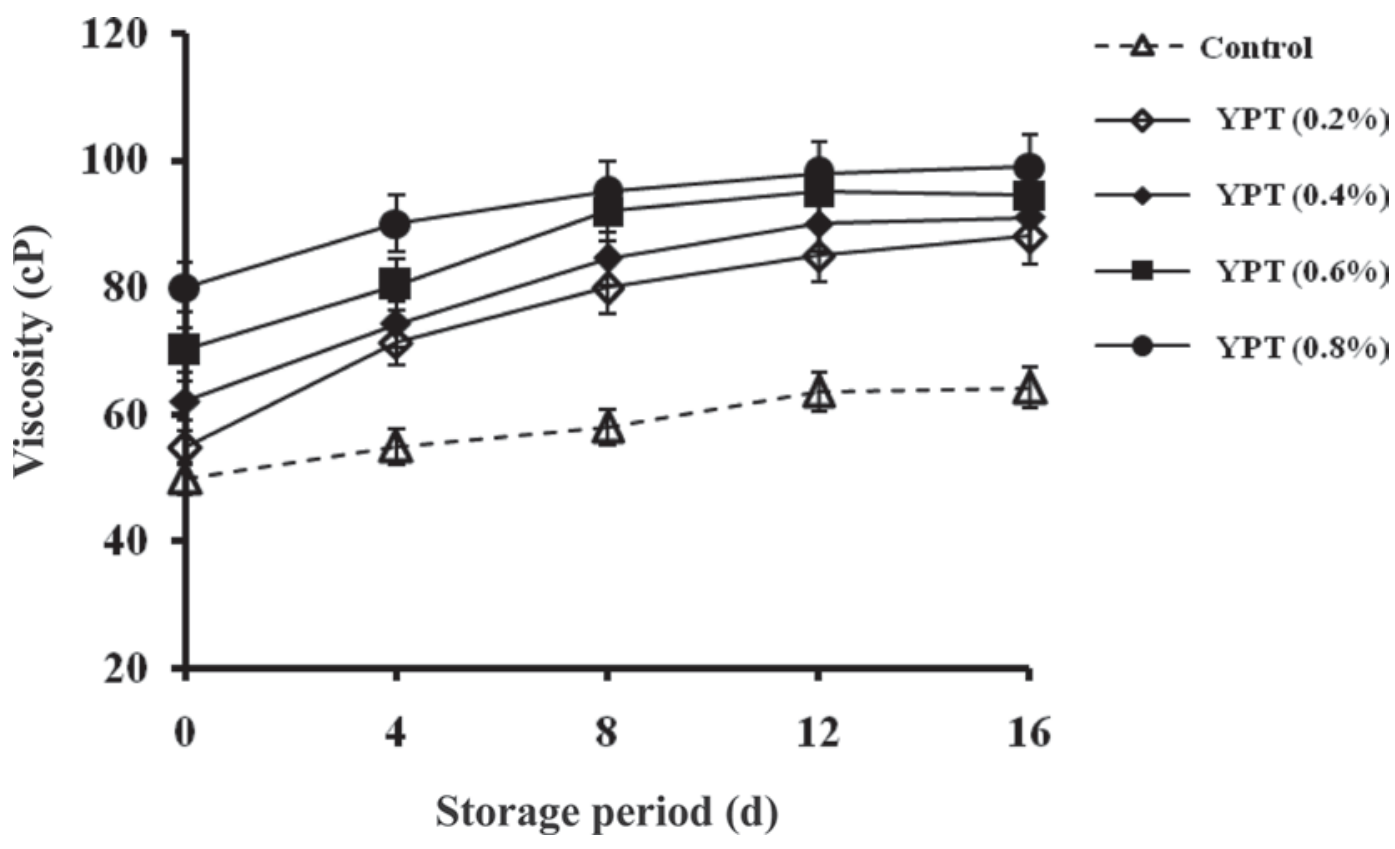

Figure 3. Changes in viscosity of powdered yam (Dioscorea opposita Thunb.; YPT)-supplemented yogurt stored at $4^{\circ} \mathrm{C}$ for $16 \mathrm{~d}$. At 0 d, yogurt had been stabilized for $24 \mathrm{~h}$.

component. On the other hand, 0.6 and $0.8 \%$ (wt/vol) YPT-supplemented yogurt showed the lowest syneresis at $16 \mathrm{~d}$ (Table 1) because of the high capacity of the YPT to hold water. Thus, as YPT addition increased, whey-off from the yogurt decreased and the highest $\mathrm{a}^{*}$ values were obtained (less greenness). However, the $b^{*}$ values increased when the storage period increased from 0 to $16 \mathrm{~d}$. The $\mathrm{b}^{*}$ values of YPT-supplemented yogurt at all concentrations $(0.2,0.4,0.6$, and $0.8 \%, \mathrm{wt} / \mathrm{vol})$ were considerably higher at $0 \mathrm{~d}$ of storage, probably due to the original yellow color of YPT. According to Needs et al. (2000), yogurt b* values can be enhanced during storage at $4^{\circ} \mathrm{C}$. Higher concentrations of YPT $(0.8 \%)$ and refrigerated storage $\left(4^{\circ} \mathrm{C}\right)$ increased the $\mathrm{b}^{*}$ value during the storage time of $16 \mathrm{~d}$.

\section{Allantoin and Diosgenin Contents}

The changes in allantoin and diosgenin contents of yogurt supplemented with different concentrations of

Table 1. Changes in color of powdered yam (Dioscorea opposita Thunb.; YPT)-supplemented yogurt stored at $4^{\circ} \mathrm{C}$ for $16 \mathrm{~d}$

\begin{tabular}{|c|c|c|c|c|c|c|}
\hline \multirow[b]{2}{*}{ Color $^{1}$} & \multirow{2}{*}{$\begin{array}{c}\text { Storage } \\
\text { period }(\mathrm{d})\end{array}$} & \multicolumn{5}{|c|}{ Concentration (\%, wt/vol) } \\
\hline & & Control & 0.2 & 0.4 & 0.6 & 0.8 \\
\hline \multirow[t]{5}{*}{$\mathrm{L}^{*}$} & $0^{2}$ & $85.88 \pm 0.67^{\mathrm{a}, \mathrm{x}}$ & $85.90 \pm 0.44^{\mathrm{a}, \mathrm{x}}$ & $85.85 \pm 0.31^{\mathrm{a}, \mathrm{x}}$ & $85.57 \pm 0.49^{\mathrm{a}, \mathrm{x}}$ & $84.89 \pm 0.40^{\mathrm{b}, \mathrm{y}}$ \\
\hline & 4 & $86.60 \pm 0.45^{\mathrm{a}, \mathrm{x}}$ & $86.18 \pm 0.56^{\mathrm{a}, \mathrm{xy}}$ & $86.22 \pm 0.61^{\mathrm{a}, \mathrm{xy}}$ & $85.88 \pm 0.27^{\mathrm{b}, \mathrm{y}}$ & $85.97 \pm 0.51^{\mathrm{b}, \mathrm{y}}$ \\
\hline & 8 & $86.23 \pm 0.25^{\mathrm{a}, \mathrm{x}}$ & $85.78 \pm 0.53^{\mathrm{ab}, \mathrm{xy}}$ & $86.13 \pm 0.49^{\mathrm{a}, \mathrm{x}}$ & $85.50 \pm 0.45^{\mathrm{b}, \mathrm{y}}$ & $84.94 \pm 0.52^{\mathrm{b}, \mathrm{z}}$ \\
\hline & 12 & $88.43 \pm 0.43^{\mathrm{a}, \mathrm{x}}$ & $88.36 \pm 0.62^{\mathrm{a}, \mathrm{x}}$ & $85.93 \pm 2.98^{\mathrm{b}, \mathrm{y}}$ & $89.19 \pm 0.50^{\mathrm{a}, \mathrm{x}}$ & $88.71 \pm 0.51^{\mathrm{a}, \mathrm{x}}$ \\
\hline & 16 & $86.42 \pm 2.23^{\mathrm{ab}, \mathrm{x}}$ & $86.75 \pm 0.76^{\mathrm{ab}, \mathrm{x}}$ & $86.79 \pm 0.63^{\mathrm{ab}, \mathrm{x}}$ & $87.17 \pm 0.59^{\mathrm{a}, \mathrm{x}}$ & $87.69 \pm 1.34^{\mathrm{a}, \mathrm{x}}$ \\
\hline \multirow[t]{5}{*}{$a^{*}$} & 0 & $2.27 \pm 0.16^{\mathrm{a}, \mathrm{x}}$ & $2.16 \pm 0.14^{\mathrm{b}, \mathrm{xy}}$ & $2.28 \pm 0.08^{\mathrm{a}, \mathrm{x}}$ & $2.05 \pm 0.13^{\mathrm{b}, \mathrm{yz}}$ & $2.00 \pm 0.12^{\mathrm{b}, \mathrm{z}}$ \\
\hline & 4 & $2.02 \pm 0.18^{\mathrm{b}, \mathrm{x}}$ & $2.17 \pm 0.20^{\mathrm{a}, \mathrm{xy}}$ & $2.13 \pm 0.18^{\mathrm{a}, \mathrm{y}}$ & $2.11 \pm 0.07^{\mathrm{a}, \mathrm{y}}$ & $2.10 \pm 0.15^{\mathrm{ab}, \mathrm{yz}}$ \\
\hline & 8 & $2.08 \pm 0.10^{\mathrm{bc}, \mathrm{y}}$ & $2.35 \pm 0.16^{\mathrm{a}, \mathrm{x}}$ & $2.14 \pm 0.15^{\mathrm{b}, \mathrm{y}}$ & $2.15 \pm 0.14^{\mathrm{b}, \mathrm{y}}$ & $2.00 \pm 0.15^{\mathrm{bc}, \mathrm{y}}$ \\
\hline & 12 & $2.15 \pm 0.09^{\mathrm{ab}, \mathrm{z}}$ & $2.34 \pm 0.23^{\mathrm{a}, \mathrm{xy}}$ & $2.09 \pm 0.35^{\mathrm{c}, \mathrm{z}}$ & $2.44 \pm 0.14^{\mathrm{a}, \mathrm{x}}$ & $2.16 \pm 0.14^{\mathrm{bc}, \mathrm{yz}}$ \\
\hline & 16 & $1.85 \pm 0.63^{\mathrm{c}, \mathrm{z}}$ & $2.41 \pm 0.23^{\mathrm{a}, \mathrm{y}}$ & $2.19 \pm 0.17^{\mathrm{b}, \mathrm{y}}$ & $2.44 \pm 0.18^{\mathrm{a}, \mathrm{y}}$ & $2.43 \pm 0.20^{\mathrm{a}, \mathrm{y}}$ \\
\hline \multirow[t]{5}{*}{$b^{*}$} & 0 & $3.03 \pm 0.53^{\mathrm{c}, \mathrm{y}}$ & $3.40 \pm 0.40^{\mathrm{ab}, \mathrm{xy}}$ & $3.67 \pm 0.26^{\mathrm{a}, \mathrm{x}}$ & $3.19 \pm 0.42^{\mathrm{c}, \mathrm{y}}$ & $3.70 \pm 0.34^{\mathrm{a}, \mathrm{x}}$ \\
\hline & 4 & $3.05 \pm 0.45^{\mathrm{c}, \mathrm{y}}$ & $3.49 \pm 0.55^{\mathrm{bc}, \mathrm{xy}}$ & $3.38 \pm 0.56^{\mathrm{bc}, \mathrm{x}}$ & $3.47 \pm 0.21^{\mathrm{b}, \mathrm{y}}$ & $3.61 \pm 0.28^{\mathrm{a}, \mathrm{x}}$ \\
\hline & 8 & $3.07 \pm 0.23^{\mathrm{c}, \mathrm{z}}$ & $3.64 \pm 0.48^{\mathrm{a}, \mathrm{x}}$ & $3.52 \pm 0.45^{\mathrm{a}, \mathrm{xy}}$ & $3.12 \pm 0.37^{\mathrm{bc}, \mathrm{yz}}$ & $3.20 \pm 0.45^{\mathrm{ab}, \mathrm{yz}}$ \\
\hline & 12 & $3.06 \pm 0.31^{c, z}$ & $3.62 \pm 0.50^{\mathrm{bc}, \mathrm{yz}}$ & $3.76 \pm 0.84^{\mathrm{bc}, \mathrm{xy}}$ & $4.31 \pm 0.66^{\mathrm{ay}}$ & $4.10 \pm 0.69^{\mathrm{ab}, \mathrm{xy}}$ \\
\hline & 16 & $3.78 \pm 0.62^{\mathrm{bc}, \mathrm{z}}$ & $3.93 \pm 0.83^{\mathrm{bc}, \mathrm{y}}$ & $4.23 \pm 0.63^{\mathrm{bc}, \mathrm{y}}$ & $4.36 \pm 0.52^{\mathrm{ab}, \mathrm{y}}$ & $5.34 \pm 0.53^{\mathrm{a}, \mathrm{x}}$ \\
\hline
\end{tabular}

\footnotetext{
${ }^{\mathrm{a}-\mathrm{c}}$ Values with different superscripts within the same column differ significantly $(P<0.05)$.

${ }^{\mathrm{x}-\mathrm{z}}$ Values with different superscripts within the same row differ significantly $(P<0.05)$.

${ }^{1}$ Measured $L^{*}, a^{*}$, and $b^{*}$ values were used as indicators of lightness, redness, and yellowness, respectively.

${ }^{2}$ The sample was obtained $24 \mathrm{~h}$ after yogurt making.
} 
Table 2. Changes in allantoin $(\mu \mathrm{g} / \mathrm{mL})$ of powdered yam (Dioscorea opposita Thunb.; YPT)-supplemented yogurt stored at $4^{\circ} \mathrm{C}$ for $16 \mathrm{~d}$

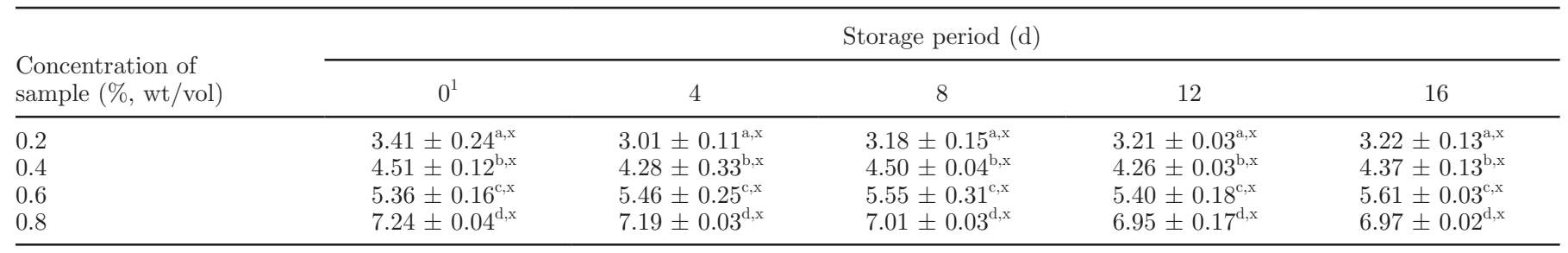

${ }^{\mathrm{a}-\mathrm{d}}$ Values with different superscripts within the same column differ significantly $(P<0.05)$.

${ }^{\mathrm{x}}$ Values with different superscripts within the same row differ significantly $(P<0.05)$.

${ }^{1}$ The sample was obtained $24 \mathrm{~h}$ after yogurt making.

YPT during $16 \mathrm{~d}$ of storage are presented in Tables 2 and 3. As expected, both allantoin and diosgenin contents were higher in samples containing a higher percentage of YPT. The content of allantoin and diosgenin was 3.41 and $4.69 \mu \mathrm{g} / \mathrm{mL}$, respectively, when yogurt was supplemented with $0.2 \%$ (wt/vol) YPT. Both components did not change quantitatively during storage periods of $16 \mathrm{~d}$. $\mathrm{Fu}$ et al. (2006) reported that the quantity of allantoin varies with the storage time of yams. Further, the type of yam and extraction process also affects the content of allantoin and diosgenin in YPT. In our preliminary study, the EYP contained a considerably lower allantoin content $(0.44 \%)$ than did raw yam powder, which contained $0.69 \%$ from the same source and variety of Dioscorea opposita Thunb. This fact confirms that the extraction process affects the content of allantoin in the same variety and source of yam.

\section{Sensory Evaluation}

The sensory attributes of YPT-supplemented yogurt stored at $4^{\circ} \mathrm{C}$ for $16 \mathrm{~d}$ are presented in Table 4. The whey-off scores for the YPT-supplemented yogurt at different concentrations $(0.2,0.4,0.6$, and $0.8 \%$, wt/ vol) and for the control were not significantly influenced by prolonged storage $(16 \mathrm{~d})$ or the addition of YPT. The color score (likeness) at 0 and $16 \mathrm{~d}$ of storage was significantly decreased $(P<0.05)$ when a greater concentration $(0.8 \%, \mathrm{wt} / \mathrm{vol})$ of YPT was added into the yogurt, probably because of the original yellow color of the yam powder. This coincided with the higher $\mathrm{b}^{*}$ value of yogurt supplemented with a higher concentration $(0.8 \%$, wt/vol) of YPT at 0 and $16 \mathrm{~d}$ of storage (Table 1). The herb and rancid scores for the yogurt samples supplement with YPT at various concentrations were not significantly affected during $16 \mathrm{~d}$ of storage $(P<0.05)$. In the taste test, it was revealed that adding YPT $(0.8 \%$, wt/vol) into yogurt samples caused a significant decrease in the sourness scores and a significant increase in the astringency scores at $16 \mathrm{~d}$ of storage $(P<0.05)$. The greater astringency scores for yogurt samples that included the YPT $(0.8 \%$, wt/ vol) were probably the result of the astringent flavor of the yam powder. Seo et al. (2009) also observed that addition of chitosan in yogurt increase the astringent value of yogurt during $16 \mathrm{~d}$ of storage. According to the texture test, the grainy and weak scores for the YPT-supplemented yogurt at $16 \mathrm{~d}$ of storage were not significantly affected by the addition of YPT $(P<$ 0.05). Finally, adding YPT into the yogurt samples did not significantly influence the overall acceptability at 0 , 4 , and $8 \mathrm{~d}$ of storage. Based on all of the sensory data obtained from the current study, it is suggested that concentrations (0.2 to approximately $0.6 \%$, wt/vol) of YPT could be used for the production of the yogurt without affecting the sensory properties.

Table 3. Changes in diosgenin $(\mu \mathrm{g} / \mathrm{mL})$ of powdered yam (Dioscorea opposita Thunb.; YPT)-supplemented yogurt stored at $4^{\circ} \mathrm{C}$ for $16 \mathrm{~d}$

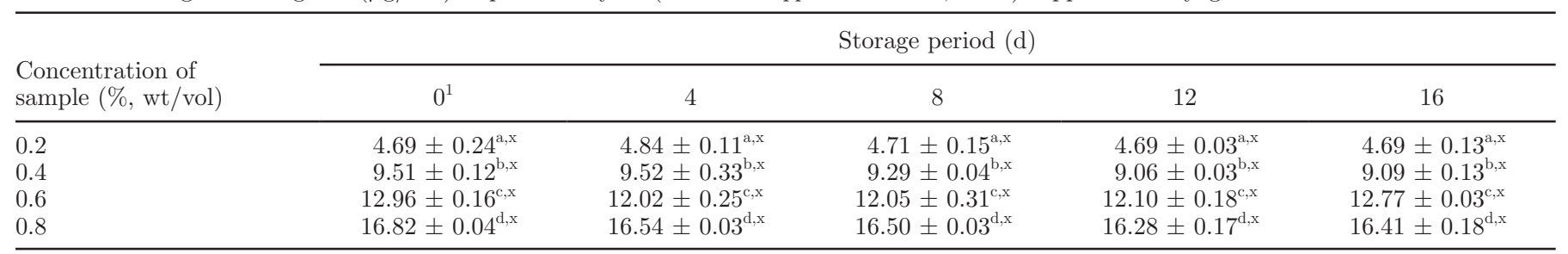

${ }^{\mathrm{a}-\mathrm{d}}$ Values with different superscripts within the same column differ significantly $(P<0.05)$.

${ }^{\mathrm{x}}$ Values with different superscripts within the same row differ significantly $(P<0.05)$.

${ }^{1}$ The sample was obtained $24 \mathrm{~h}$ after yogurt making. 
Table 4. Sensory characteristics of powdered yam (Dioscorea opposita Thunb.; YPT)-supplemented yogurt stored at $4^{\circ} \mathrm{C}$ for $16 \mathrm{~d}^{1}$

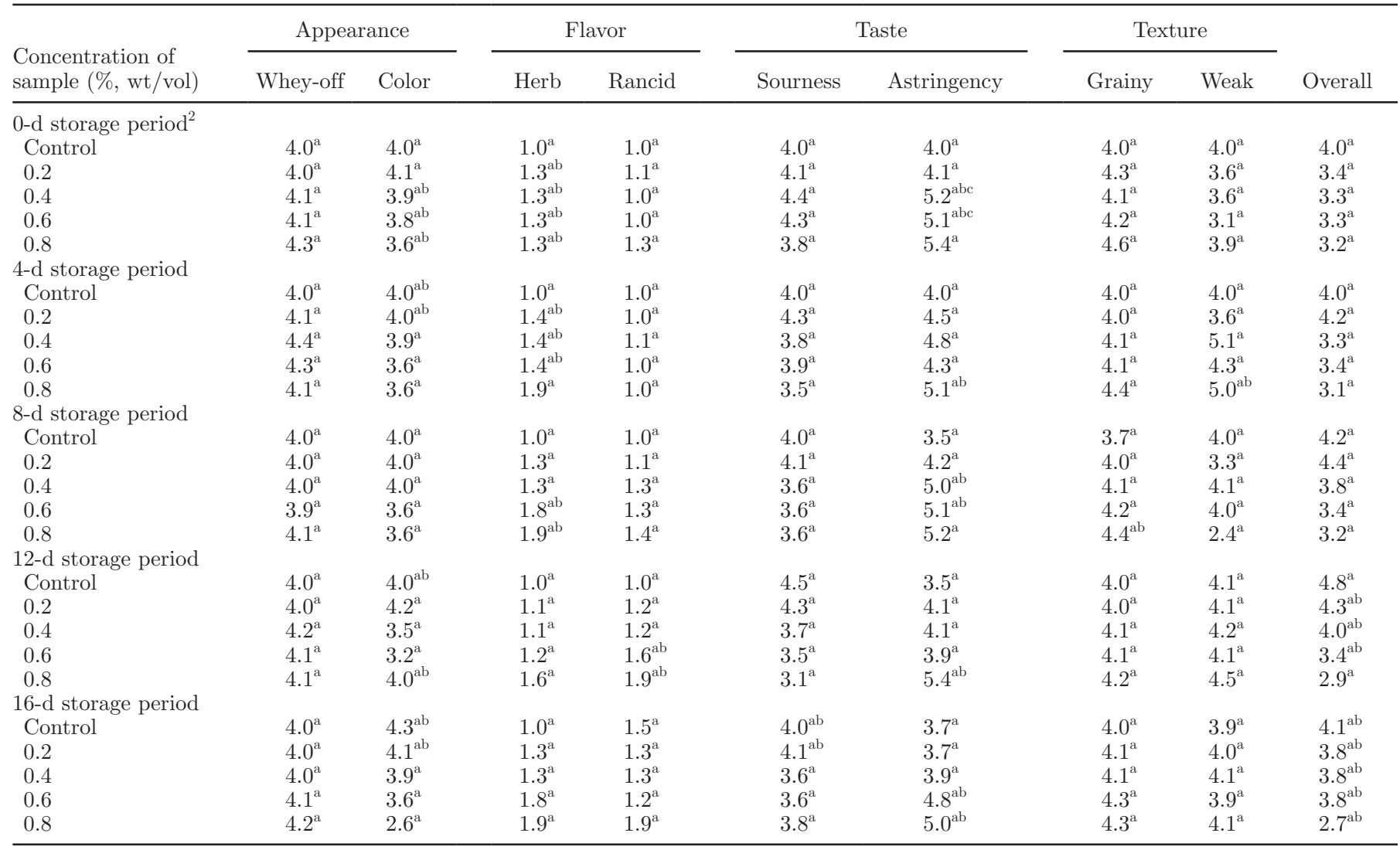

${ }^{\mathrm{a}-\mathrm{c}}$ Values with different superscript letters within the same column differ significantly $(P<0.05)$.

${ }^{1}$ The scale of appearance, flavor, taste, and texture scores was as follows: $1=$ very weak, $4=$ moderate, $7=$ very strong.

${ }^{2}$ The sample was obtained $24 \mathrm{~h}$ after yogurt making.

\section{CONCLUSIONS}

The results of this study show that yams can be used as a novel ingredient in yogurt production. From the perspective of improved health benefits, YPT-supplemented yogurt acts as a functional yogurt, which can be supplemented with allantoin and diosgenin without any modification during fermentation and storage of yogurt at $16 \mathrm{~d}$. The data on the $\mathrm{pH}$, TA, viscosity, allantoin, diosgenin, color, and microbial and sensory analysis obtained from the current study indicated that concentrations of 0.2 to approximately $0.6 \%$ (wt/vol) YPT could be applicable in yogurt development. This broadens the application of YPT in yogurt and opens the way for the development of other fermented foods for health benefits.

\section{ACKNOWLEDGMENTS}

This study was supported by a grant of the Brain Korea 21 Project in Seoul, Republic of Korea.

\section{REFERENCES}

Abodjo Kakou, C., S. Tagro Guehi, K. Olo, F. Akissi Kouame, R. Koffi Nevry, and C. Marina Koussemon. 2010. Biochemical and microbial changes during traditional spontaneous lactic acid fermentation process using two varieties of cassava for production of a "Alladjan" starter. Int. Food Res. J. 17:563-573.

Amaya-Llano, S. L., A. L. Martínez-Alegría, J. J. Zazueta-Morales, and F. Martínez-Bustos. 2008. Acid thinned jicama and maize starches as fat substitute in stirred yogurt. LWT-Food Sci. Technol. 41:1274-1281.

Asiedu, M., and A. I. Sanni. 2002. Chemical composition and microbiological changes during spontaneous and starter culture fermentation on Eman Ne-Setaakye, a West African fermented fishcarbohydrate product. Eur. Food Res. Technol. 215:8-12.

Banon, S., and J. Hardy. 1992. A colloidal approach of milk acidification by glucono-delta-lactone. J. Dairy Sci. 75:935-941.

Coulin, P., Z. Farah, J. Assanvo, H. Spillmann, and Z. Puhan. 2006. Characterisation of the microflora of attiéké, a fermented cassava product, during traditional small-scale preparation. Int. J. Food Microbiol. 106:131-136.

Dalgleish, D. G., and A. J. R. Law. 1988. pH-induced dissociation of bovine casein micelles. I. Analysis of liberated caseins. J. Dairy Res. 55:529-538.

Fu, Y.-C., L.-H. A. Ferng, and P.-Y. Huang. 2006. Quantitative analysis of allantoin and allantoic acid in yam tuber, mucilage, skin and bulbil of the Dioscorea species. Food Chem. 94:541-549. 
Garnick, J. J., B. Singh, and G. Winkley. 1998. Effectiveness of a medicament containing silicon dioxide, aloe, and allantoin on aphthous stomatitis. Oral Surg. Oral Med. Oral Pathol. Oral Radiol. Endod. 86:550-556.

Hariprakash, C. S., and B. Nambisan. 1996. Carbohydrate metabolism during dormancy and sprouting in yam (Dioscorea) tubers: Changes in carbohydrate constituents in yam (Dioscorea) tubers during dormancy and sprouting. J. Agric. Food Chem. 44:3066-3069.

Jaziri, I., M. Ben Slama, H. Mhadhbi, M. C. Urdaci, and M. Hamdi. 2009. Effect of green and black teas (Camellia sinensis L.) on the characteristic microflora of yogurt during fermentation and refrigerated storage. Food Chem. 112:614-620.

Lin, J.-T., and D.-J. Yang. 2008. Determination of steroidal saponins in different organs of yam (Dioscorea pseudojaponica Yamamoto). Food Chem. 108:1068-1074.

Lourens-Hattingh, A., and B. C. Viljoen. 2001. Yogurt as probiotic carrier food. Int. Dairy J. 11:1-17.

Ma, H.-Y., Z.-T. Zhao, L.-J. Wang, Y. Wang, Q.-L. Zhou, and B.X. Wang. 2002. Comparative study on anti-hypercholesterolemia activity of diosgenin and total saponin of Dioscorea panthaica. China J. Chinese Materia Medica (Zhongguo Zhong Yao Za Zhi) 27:528-531.

Myoda, T., Y. Matsuda, T. Suzuki, T. Nakagawa, T. Nagai, and T. Nagashima. 2006. Identification of soluble proteins and interaction with mannan in mucilage of Dioscorea opposita Thunb. (Chinese yam tuber). Food Sci. Technol. Res. 12:299-302.

Needs, E. C., M. Capellas, A. P. Bland, P. Manoj, D. MacDougal, and G. Paul. 2000. Comparison of heat and pressure treatments of skim milk, fortified with whey protein concentrate, for set yogurt preparation: Effects on milk proteins and gel structure. J. Dairy Res. 67:329-348.

Sagara, K., K. Suto, M. Kawaura, and T. Yoshida. 1988. Analysis of Dioscorea rhizoma. Pharm. Technol. Japan 4:811-813.
Sahan, N., K. Yasar, and A. A. Hayaloglu. 2008. Physical, chemical and flavour quality of non-fat yogurt as affected by a $\beta$-glucan hydrocolloidal composite during storage. Food Hydrocoll. 22:12911297.

SAS Institute. 2002. SAS User's Guide: Statistics. Version 9.0. Cary, $\mathrm{NC}$.

Seo, M. H., S. Y. Lee, Y. H. Chang, and H. S. Kwak. 2009. Physicochemical, microbial, and sensory properties of yogurt supplemented with nanopowdered chitosan during storage. J. Dairy Sci. 92:5907-5916.

Shin, K. O., J. R. Jeon, J. S. Lee, J. Y. Kim, C. H. Lee, S. C. Kim Y. Yu, and D. H. Nam. 2006. Lactic acid fermentation of Chinese Yam (Dioscorea batatas Decne) flour and its pharmaceutical effect on gastrointestinal function in rat model. Biotechnol. Bioproc. Eng. 11:240-244.

Shirai, K., G. Pedraza, M. Gutierrez-Durán, V. M. E. Marshall, S. Revah-Moiseev, and M. García-Garibay. 1992. Production of a yogurt-like product from plant foodstuffs and whey. Substrate preparation and fermentation. J. Sci. Food Agric. 59:199-204.

Singh, M., and S. Kim. 2009. Yogurt fermentation in the presence of starch-lipid composite. J. Food Sci. 74:C85-C89.

Ueda, H., and T. Sasake. 1956. Chemical studies on the plants of Di oscorea species. J. Pharm. Soc. 76:745.

Williams, R. P. W., O. Glagovskaia, and M. A. Augustin. 2004. Properties of stirred yogurts with added starch: Effects of blends of skim milk powder and whey protein concentrate on yogurt texture. Aust. J. Dairy Technol. 59:214-220.

Yang, D.-J., T.-J. Lu, and L. S. Hwang. 2003. Isolation and identification of steroidal saponins in Taiwanese yam cultivar (Dioscorea pseudojaponica Yamamoto). J. Agric. Food Chem. 51:64386444 